\title{
The Effect of Cooperative Learning in Blended Learning Environment on Students' Learning Achievement: A True-Experimental Study
}

\author{
$\operatorname{Ridwan}^{1 *}$ \\ ${ }^{1}$ Teacher Training and Education Faculty of Borneo Tarakan University, Tarakan, North \\ Kalimantan Province, Indonesia \\ Corresponding Author* Email: ridwan.fkipubt@gmail.com
}

\begin{abstract}
The combined blended learning with other teaching strategies has become a considerable concern for educators around the world nowadays. The characteristics of such a blend that can be retrieved at any time, in any place, multi-users, and all its simplicity have made it a very appropriate pedagogical medium for the development of education. This study was conducted to investigate the effect of Cooperative Learning in Blended Learning (CLBL) environment on teaching. The students' learning achievement by comparing CLBL environment and teacher-led instruction in BL environment and the students' responses to such learning environment were analyzed. A trueexperimental study was employed at the English Education Department of Teacher Training and Education Faculty of Borneo Tarakan University in the 2019-2020 academic year. Sixty-four of fifth-semester students were matched and chosen at random to be a half of them as the experimental class and control class for another half. The main instruments used to gain the intended data were a pretest, a posttest, and an interview guide. The results of the independent samples t-test indicated that the CLBL environment yielded a significant effect on the students' learning achievement. The students who learned through the CLBL environment far outperformed those who studied through teacher-led instruction in BL environment. This was proved by the probability value of the t-test on the posttest (0.025), which was smaller than the level of significance (0.050). In addition, the students were positive about the productiveness of the CLBL environment, and they found that it really helped them learn.
\end{abstract}

Keywords: Cooperative Learning (CL), Blended Learning (BL), e-learning, and Learning Achievement

\section{INTRODUCTION}

The utilization of advanced technologies in instruction is very rapidly grown over the last few years. E-learning innovation and applications such as computers, mobile devices, virtual class, multimedia, internet, telecommunication and so on [1][2] are making more personalized instruction. Subsequently, the conventional teaching approach is blurring absent, plausible advancements in ICT have risen as a modern scene in the instructional framework where the classroom face-to-face learning and online computer-mediated learning are combined to complement learning, improve access and convenience, and cost efficiency [3]. The characteristics of $\mathrm{BL}$, which are always accessible at any time and place, multi-user and offering all its simplicity, have made it a very suitable learning medium for educational development [4].

Many studies have been carried out on the application of face-to-face cooperative learning. Yet, there were only a few reports originated on the use of cooperative learning in a blended learning (CLBL) environment. Implementing cooperative learning in such an environment is challenging for the teachers. The integration of CL into a BL circumstance should be planned based on the learning outcomes, resources, student characteristics, and the preparation of course materials. It needs commitment and willingness to take risks, time, and planning [5]. As Arends [6], states an overall plan or pattern of learning 
can help students learn specific types of knowledge, attitudes or skills.

Blended learning (BL) is a combination of the use of technologies, activities, and events to create optimal learning programs according to student characteristics. "Blended" is a term which means that conventional instruction is complemented with electronic presentations [7]. In the same sense, Stein \& Graham [8] state that blended learning is a hybrid of faceto-face classroom interaction with online instruction to create active, proficient, and adaptable learning. Furthermore, Yapici [9] approves that blended learning is the best combination of face-to-face classroom interaction and online interaction.

In blended learning, e-learning settings are integrated with face-to-face conventional activities using various types of approaches [10]. It requires a systematic strategy and approach in combining technology and face-to-face learning. As Krause in Bath \& Bourke [11] says that blended learning is attained in an instruction environment where there is an efficient integration of multiple delivery modes, teaching methods and learning styles, resulting in the adoption of strategic and systematic models to the use of ICT combined with the best characteristics of face-to-face classroom instruction.

One of the instructional approaches that can be applied in a blended mode is cooperative learning. Cooperative learning (CL) is a solution to facilitate interaction. It is one of the most inspired and popular teaching approaches to learning for the present century. It is one of the most inspiring and prevalent teaching approaches in this century. It is hypothetically established and expansively explored in educational settings, which is considered to encourage the attainment of all characteristics of students [12]. In education, cooperative learning was introduced through the work of Johnson and Johnson in 1966. They define cooperative learning as the use of small groups of students who work together to learn from each other to get maximum learning results. There are five essential elements of cooperative learning: (a) positive interdependence, (b) individual accountability and personal responsibility, (c) promotive interaction, (d) appropriate use of social skills, and (e) group processing [13].

There were few empirical studies that investigated the combination of cooperative learning in a BL environment and the terms associated with it. They are EL-Deghaidy \&
Nouby [14] with "blended e-learning cooperative approach (BeLCA)", Howison \& Finger [15] with "cooperative education placement through the use of learning management system functionalities", Hariadi [16] with "web-based cooperative learning", Yapici [9] with "blended cooperative learning environment (BCLE)", Bosch et al. [5] with "cooperative learning into the combined blended learning design model" (CL in BL environment), Husaini et al. [17] with "cooperative models based on blended learning", and Suartini et al. [18] with "blended learning in cooperative learning."

In this present study, the term proposed by Bosch et al. [5] was used, namely, CL in BL environment which means that the students work in small diverse groups to learn from each other through the combination of face-to-face activities and online (synchronous and asynchronous) activities into three forms of the learning environment: contact sessions, online team challenges, and group tasks.

There is limited research carried out to compare the application of cooperative learning and teacher-led instruction under the blended learning environment. The current study, therefore, attempted to investigate the effect of using blended learning with different teaching and learning environment, in this case, the comparison between CLBL environment and teacher-led instruction in BL environment in teaching Research Method in English Language Teaching course for the fifth-semester students of English Education Department of Borneo Tarakan University. In addition, this study also identified the students' responses to the application of the CLBL environment. For this reason, the following questions were offered:

1) Is there any significant effect on learning achievement between the CLBL environment and teacher-led instruction in BL environment at the fifth-semester students of the English Education Department of Borneo Tarakan University?

2) What are the students' responses to the implementation of the CLBL environment?

\section{RESEARCH METHOD}

\subsection{Design}

This study employed a trueexperiment with a pretest-posttest control group design. Gay et al. [19] state that all designs in true-experiment control almost all internal and external validity threats. There is 
one feature that does not exist in other designs, namely, a random distribution of participants.

\subsection{Participants}

This participants of this study were the students from the fifth-semester of the English Education Department of Borneo Tarakan University during the odd semester of the 2019-2020 academic year. To explore the effects of the CLBL environment on students' learning achievement, a homogenous pair of independent samples from two intact classes participated in this study. To do so, the pretest was given to students before the experiment in order to have matched sets of subjects which were then distributed at random into the experimental group and the control group [20].

Table 1. Demographic information on research subjects

\begin{tabular}{|c|c|c|c|c|c|}
\hline \multirow{2}{*}{ Group } & \multirow{2}{*}{$\mathrm{N}$} & \multicolumn{2}{|c|}{ Gender } & \multirow{2}{*}{ Age Range } & \multirow{2}{*}{ Learning Approach } \\
\hline & & Male & Female & & \\
\hline Experimental & 34 & 10 & 24 & $20-22$ & $\begin{array}{l}\text { Cooperative learning in } \\
\text { BL environment }\end{array}$ \\
\hline Control & 34 & 9 & 25 & $20-22$ & $\begin{array}{l}\text { Teacher-led instruction } \\
\text { in BL environment }\end{array}$ \\
\hline
\end{tabular}

\subsection{Instruments}

The instruments that were used to gather quantitative data were a pretest and a posttest. The pretest and posttest were comprised of 100 multiple-choice questions. The test items were selected from Practice Quizzes [21]. To avoid the effect of pretest sensitization [21], the test items in the posttest were different from the pretest but were of a similar difficulty level. The qualitative data were collected from semistructured interviews [22]. The students were asked about their responses on the advantages, disadvantages, and their recommendation for future improvement in using the CLBL environment [9].

\subsection{Data Gathering Procedures}

This study was accomplished over a period of 16 weeks or four months, which was adequate for the students to fulfil all the required tasks and activities. The first stage of the study was a pretest which was distributed to both classes of students. The second stage of the study consisted of the process of treatment. The third stage was a posttest; the same procedure as in the pretest was conducted. And the last stage was an interview.

In the experimental group, a CLBL environment which was adopted from Bosch et al. [5], was used as the process of treatment. It is the combined blended learning design model which is integrated with cooperative learning. The treatment was allocated into three key components of CLBL, namely: contact sessions, online team challenges, and group tasks.

The contact sessions were face-to-face classroom interaction sessions. In each contact session, the lecturer used cooperative learning strategies. These activities were carried out in small groups of 4-5 students who were chosen heterogeneously.

The online team challenges were fully online interactive sessions. The online team challenges were comprised of some team activities that they were required to complete and submit some tasks on BeL (Borneo eLearning) as the institution learning management system. The students were given a number of tasks in groups. All the activities were organized and announced to the students that they understood what was required from them at all times. The team challenge tasks such as (a) learning manuals were available in BeL, such as learning contract, a learning program for a semester, course materials, and guidelines; (b) online discussion forums initiated by each group members; and (c) individual online quizzes but the results were calculated as a group score.

The group tasks were the integration of both face-to-face and online. For these tasks, the students had to gather face-to-face more than once to be able to accomplish the tasks, such as: making a video presentation to explain the content of the topic being discussed, reviewing research reports on ten different kinds of research methods, and making a draft of a research proposal. They worked on the tasks face-to-face and had to submit the tasks online.

In the control group, the lecturer provided BL using a teacher-led instruction environment. The course content materials and tasks were the same as those in the experimental group. The differences were in the teaching procedures and tasks. In the 
process of instruction, the lecturer acted as a dominant person most of the time. He explained the materials in face-to-face classroom activities and initiated a discussion in discussion forums in BeL. There also were group tasks in the control class, but the formation of the group members was based on "who likes whom".

Afterwards, the representative students were asked for an interview. Ten students from an experimental group were randomly chosen according to the results of their posttest, e.g., high, moderate, and low achievers. The interview was done within one week after the posttest. The interview results were recorded and transcribed, respectively, for analysis [23].

\subsection{Data Analysis}

For statistical analysis of pretest and posttest results, SPSS software (IBM SPSS Statistics version 27.0) was used to analyze the obtained data. The results of the Kolmogorov-Smirnov test and Levene's test as the requirements for the hypothesis testing indicated that the data correspond to the use of parametric statistics $(\alpha>0.05)$. Descriptive statistical procedure and inferential statistical procedure (independent samples t-test) were employed to examine the quantitative data. The level of significance was assumed to be 0.05 . Regarding qualitative data, content analysis was used [9].

\section{FINDINGS AND DISCUSSION}

\subsection{Findings}

3.1.1 The Effect of CLBL environment on Students' Learning

Achievement

The purpose of this study was to analyze the differences between the achievement scores of the experimental class and that of the control class, taking into account these two variables, to test how effective the learning perceived by the students was. A t-test for independent samples was conducted to determine if the teaching had a significant effect on students' learning achievement. The data are set out in Table 2.

Table 2. The independent samples t-test between experimental group and control group

\begin{tabular}{clcccccc}
\hline Test & \multicolumn{1}{c}{ Groups } & N & Mean & SD & $\begin{array}{c}\text { T- } \\
\text { value }\end{array}$ & $\begin{array}{c}\text { P- } \\
\text { value }\end{array}$ & Remark \\
\hline Pretest & Experimental Grour & 34 & 37.56 & 6.36 & -0.037 & 0.970 & $\begin{array}{c}\text { No } \\
\text { Control Group }\end{array}$ \\
& 34 & 37.62 & 6.66 & & & Significant \\
\hline Posttest & Experimental Grour & 34 & 79.65 & 10.65 & 2.294 & 0.025 & Significant \\
& Control Group & 34 & 73.00 & 13.11 & & & \\
\hline
\end{tabular}

As it is seen in Table 2, at first in the pretest, the students from both groups arrived at the equivalent level of prior knowledge of content course materials. It is shown that there was no significant difference ( $\mathrm{t}$-test $=$ 0.037, $\mathrm{p}=0.970$ ) between the learning achievement in the pretest mean score of the experimental group (37.56) and that of the control group (37.62). However, at last, as such, the result of the t-test in the posttest was significant. It is statistically proven that the achievement in the posttest mean score of the experimental group (79.65) was greater than that of the control group (73.00), which yielded the t-test (2.294) with a $p$-value $(0.025)$. This has resulted that, by alternative conjecture, there was a difference in statistical significance between the two groups (marks given by students in the experimental class and the control class, respectively). The results of this study reflect the effectiveness of the teaching program, in this case, the application of the CLBL environment.

After all, the gain scores [24] were needed to determine the difference in the scores between pretest and posttest, which were obtained by the students. Gain score (ngain) was analyzed to identify the level of learning effectiveness after applying treatment from both the experimental class and the control class. The results of the gain scores are presented in Table 3:

Table 3. The gain scores of the experimental group and control group

\begin{tabular}{lcc}
\hline \multicolumn{1}{c}{ Groups } & N-Gain & Remark \\
\hline $\begin{array}{l}\text { Experimental } \\
\text { group }\end{array}$ & 67.87 & Moderate \\
Control group & 57.46 & Moderate \\
\hline
\end{tabular}


$\mathrm{N}$-gain scores from pretest and posttest obtained by students from both groups indicated that their knowledge of content materials improved. There were three categories of different levels of effectiveness, namely high, moderate, and low. In this study, the n-gain scores obtained by both groups were in the "moderate" level of improvement effectiveness (67.87 and 57.46, respectively). Although they were at the same level, an experimental group got a higher proportion of learning effectiveness.

\subsubsection{The Students' Responses to CLBL environment}

This is to seek to determine how well the students think they learnt through a blended learning environment. The interview responses were categorized and coded into the topics: advantages, disadvantages, and recommendation for the use of CLBL environment as follows:

\section{The advantages of the CLBL environment}

"Everyone in my group was helpful because each of us had to be responsible for explaining every piece of course material." (S1)

"At first we were quite shy to express ideas, but then we were accustomed to explain things relating to topic being discussed. We support each other and value the other's opinions." (S2)

"I like to study together with my friends. I can learn from them. I can know the misconception of the topic by my friends, because at the end of discussion, the lecturer gives clarification when we have face-toface classroom meetings or drops comments in discussion forum in BeL." (S3)

"The learning materials provided in BeL give me time to learn early or anytime I want to learn during the week, then I can prepare myself for group discussion in the classroom or in the BeL." (S4)

"We have to support each other to understand the materials, because at the end of a topic discussion there will be individual quiz that will be calculated as a group score." (S5) "I can learn a lot from my fellow friends in my group as well as from other groups. I can learn from the video presentations with interesting slides uploaded by some other groups. It's really fun for me" (S6)
"Studying using BeL is interesting, I even take advantage of learning from posting history of discussion forums." (S8)

"We have plenty of time to discuss via online. We just type our opinions or comments in chat box of BeL at any time we want. I also get something from my classmates from their postings. If it is compared to classroom discussion, there will be only few students participate and always the same person." (S9)

\section{The disadvantages of the CLBL}

\section{environment}

"Sometimes, the internet connection is slow down or suddenly missing. Or sometimes, the BeL cannot be accessed, even I have excellent connection, may be the electricity was black out in the campus." (S4) "Too many quizzes." (S5)

"There are many assignments, but I think it is OK, it is for our sake of knowledge." (S6)

"I don't like to give comments or reply other friends' posts, but I like to see their posts and I like to study by myself." (S8)

"It was lot of fun to work with friends, but I sometimes found difficult to reach the access in BeL because of internet connection and of course we have to spend extra internet data package." (S10)

\section{The recommendations for the improvement} of the CLBL environment

"I like if other subjects use blended learning, we can spend time to learn rather than to prepare ourselves to go to campus." (S1)

"The BeL should be made simple and easy to access." (S4)

"The university staff should provide students strong connection hot spots in the classrooms and around campus" (S10)

\subsection{Discussion}

Two main objectives directed this study. The first objective was to investigate whether the CLBL environment could have an effect on the students' learning achievement. The second objective was to identify the students' responses to the application of the CLBL environment.

A significant enhancement in terms of students' learning achievement was found 
between the CLBL environment and the teacher-led instruction in the $\mathrm{BL}$ environment. These results indicated that the CLBL environment was more effective in teaching a research method in ELT course than teacher-led instruction in the same BL context.

The results of students' responses indicated that they appreciated CL in blended learning circumstances. They were aware of the roles of being a member of cooperative learning and the importance of integrating technology into classroom instruction. Generally, the interview indicated that the students were positive about the productiveness of the CLBL environment. It seemed to be prominent in the students' learning experience. First, the students appreciated the convenience of establishing their own pace of learning and independent work. Second, the students' self-regulation has proved to be an important factor in a blended learning environment to help them learn the most, although they were sometimes distracted by internet connection. Finally, the students normally thought that CL in blended learning facilitated them to achieve their learning objectives and that the learning was valuable and exciting. Yet, they also found it difficult to complete and submit a lot of tasks and felt that the course program had daily quizzes (progression tests) that could burden them.

These results might be reasonable since the CLBL environment can contribute to the following aspects: (a) help students relax to communicate their opinions [17], (b) facilitate students to participate and to ensure peer-tutoring [25], (c) provide students with a great deal with classroom community sense, in terms of that they had the responsibility of group learning [9], (d) improve students' presentation skills [26], (e) maintain individual accountability [27], (f) encourage students as independent learners, and $(\mathrm{g})$ enhance social interaction where students interact with the teacher, learning resources, and other students that allow themselves to perceive as a positive interdependence.

There are several factors considered to be the cause to better learning outcomes when implementing the CLBL environment are: (1) based on a constructivist view, (2) able to motivate and promote the active participation of learners in the process of learning, and (3) more superior [16].

However, the teacher needs to consider the following aspects in order to employ cooperative learning in blended learning instruction effectively. They are: (a) teacher competencies, especially technological competence and pedagogical competence [28], (b) student characteristics, material characteristics, and supporting devices, (c) learning outcomes, (d) blended learning characteristics, (e) cooperative characteristics, (f) learning elements [29] by determining syntax of learning, social systems, principles of reaction, supporting structures, and impact of instruction.

\section{CONCLUSION}

The CLBL environment on Research Method in English Language Teaching subject for the fifth-semester students of the English Education Department of Borneo Tarakan University can be drawn a conclusion that the students succeeded great learning outcomes by the end of sixteen meetings of a learning program in the blended format between cooperative learning and teacher-led instruction. Findings indicate that the proposed teaching program using the CLBL environment far outperformed the BL using teacher-led instruction. The students were satisfied with the challenging teaching and learning process introduced through $\mathrm{CL}$ in blended learning, as they were able to learn from each other and gain maximum learning outcomes. The students were also favorable about the productiveness of CL in a blended learning environment. When appropriately implemented, CL in blended learning can reinforce the learning process by increasing the amount of learning effort compared to that of classroom learning. The CL in a blended learning environment has the potential to emerge as a major instructional model in the future.

\section{ACKNOWLEDGMENTS}

The author is grateful to the Faculty of Teacher Training and Education, Borneo Tarakan University, North Kalimantan, Indonesia, for affording the opportunity to work and for support and attention. The deepest gratitude is also addressed to the Directorate of Learning, Ministry of Research, Technology and Higher Education, Indonesia, for offering a grant through PDS (Lecturer Teaching Program at School).

\section{REFERENCES}

[1] M. A. Alseweed, "Students, achievement and attitudes toward using traditional learning , blended learning, and virtual classes learning in teaching and learning at the university level," Studies in Literature and Language, vol. 6, no. 
1. pp. 65-73, 2013.

[2] C. M. Tang and L. Y. Chaw,

"Readiness for Blended Learning: Understanding Attitude of University Students," Int. J. cyber

Soc. Educ., vol. 6, no. 2, pp. 79-100, 2013, doi: 10.7903/ijcse.1086.

[3] C. C. Nsofor, A. E. Umeh, B. Ahmed, and I. D. Sani, "Blended Learning Environment: An Innovative Pedagogical\Approach for Redefining Higher Education in Nigeria," Res. Humanit. Soc. Sci., vol. 4, no. 26, p. 8, 2014.

[4] Ridwan, H. Hamid, and I. Aras, "Blended Learning in Research Statistics Course at the English Education Department of Borneo Tarakan University," Int. J. Emerg. Technol. Learn., vol. 15, no. 7, 2020, doi: 10.3991/IJET.V15I07.13231.

[5] C. Bosch, E. Mentz, and G. M. Reitsma, "Integrating cooperative learning into the combined blended learning design model: Implications for students' intrinsic motivation," Int. J. Mob. Blended Learn., vol. 11, no. 1, pp. 58-73, 2019, doi: 10.4018/IJMBL.2019010105.

[6] R. I. Arends, Learning to Teach, Ninth Edit. New York: McGrawHill Companies, 2012.

[7] J. Bersin, The Blended Learning Book. Best Practices, Proven Methodologies and Lesson Learned. San Francisco: Pfeiffer, 2004.

[8] J. Stein and C. R. Graham, Essentials for Blended Learning: A Standards-Based Guide. New York: Routledge, 2014.

[9] İ. Ü. Yapici, "Effectiveness of Blended Cooperative Learning Environment in Biology Teaching: Classroom Community Sense, Academic Achievement and Satisfaction," J. Educ. Train. Stud., vol. Vol. 4, no. 4, pp. 269-280, 2016, doi: 10.11114/jets.v4i4.1372.

[10] B. Ghirardini, E-learning methodologies: A guide for designing and developing e-learning courses. 2011.

[11] D. Bath and J. Bourke, Getting Started with Blended Learning. Australia, 2010.

[12] S. Yaduvanshi and S. Singh, "Students in Biology through Structured Cooperative Learning ( STAD Method )," Educ. Res. Int., vol. 2019, 2019.

[13] D. W. Johnson and R. T. Johnson, "An educational psychology success story: Social interdependence theory and cooperative learning," Educ. Res., vol. 38, no. 5, pp. 365-379, 2009, doi: 10.3102/0013189X09339057.

[14] H. EL-Deghaidy and A. Nouby, "Effectiveness of a blended elearning cooperative approach in an Egyptian teacher education programme," Comput. Educ., vol. 51, no. 3, pp. 988-1006, 2008, doi: 10.1016/j.compedu.2007.10.001.

[15] S. Howison and G. Finger, "Enhancing cooperative education placement through the use of learning management system functionalities : A case study of the Bachelor of Applied Management program," Asia-Pacific J. Coop. Educ., 2010.

[16] B. Hariadi, "Web-based Cooperative Learning, Learning Styles, and Students' Learning Outcomes," J. Cakrawala Pendidik., vol. 34, no. 2, pp. 160-170, 2015, doi: 10.21831/cp.v2i2.4821

[17] A. Husaini, H. Syarifuddin, and U. Usmadi, "The Practicality of Learning Devices Cooperative Models Based on Blended Learning to Improve Learning Outcomes of 10th-Grade MA Students," Int. J. Trends Math. Educ. Res., vol. 2, no. 3, p. 157, 2019, doi: 10.33122/ijtmer.v2i3.121.

[18] T. Suartini, S. Elvyanti, E. A. Juanda, and T. Pramanik, "Development of Model Blended Learning in Cooperative Learning for Technology and Engineering skills in vocational education," in Asia Proceedings of Social Sciences, 2019, vol. 5, no. 1, pp. 11-18.

[19] L. R. Gay, G. E. Mills, and P. Airasian, Educational Research: Competencies for Analysis and Applications, Tenth Edit. New Jersey: Pearson Education, Inc., 2012.

[20] K. S. Bordens and B. B. Abbott, Research Design and Methods: A Process Approach, Eighth Edi. New York: McGraw-Hill Companies, Inc., 2011.

[21] L. R. Gay, G. E. Mills, and P. Airasian, Educational Research: Competencies for Analysis and 
Applications, Eighth Edi. Pearson Education, Inc., 2006.

[22] K. Roulston, Reflective Interviewing: A Guide to Theory and Practice. London: Sage Publications, Ltd., 2010.

[23] U. Flick, Designing Qualitative Research. London: SAGE Publications Ltd, 2007.

[24] R. R. Hake, “Analyzing Change/Gain Scores," 1999, doi: 10.24036/ekj.v1.i1.a10.

[25] Y. W. Lam, K. F. Hew, and K. F. Chiu, "Improving argumentative writing: Effects of a blended learning approach and gamification," Lang. Learn. Technol., vol. 22, no. 1, pp. 97-118, 2017, [Online]. Available: https://hub.hku.hk/handle/10722/243 899.

[26] V. Gandhi, Z. Yang, and A. Mahdi, "Project-based cooperative learning to enhance competence while teaching engineering modules," Int. J. Contin. Eng. Educ. Life-Long Learn., vol. 27, no. 3, pp. 198-208, 2017, doi:

10.1504/IJCEELL.2017.084839.

[27] E. Reiser, "Blending Individual and Group Assessment: A Model for Measuring Student Performance," J. Scholarsh. Teach. Learn., vol. 17, no. 4, pp. 83-94, 2017, doi: 10.14434/josotl.v17i4.21938.

[28] S. Tosun, "The Effects of Blended Learning on EFL Students' Vocabulary Enhancement," Procedia - Soc. Behav. Sci., vol. 199, pp. 641-647, 2015, doi: 10.1016/j.sbspro.2015.07.592.

[29] B. Joyce, M. Weil, and E. Calhoun, Models of Teaching, Ninth Edit. Boston: Pearson Education, Inc., 2015. 